\title{
Haemarthrosis in "Contusion" Injuries of the Elbow-joint
}

\author{
J. GARDEN, ${ }^{*}$ M.B., F.R.C.S.ED. ; J. H. MILLER, $\dagger$ M.B., F.R.C.S.ED., F.R.C.S.GLAS.
}

There are few references in the literature to simple contusion or sprain injuries of the elbow-joint, and it is obvious that opportunities to elucidate their basic pathology must be rare. Previous descriptions have been confined to a combination of pain, slight swelling, and limitation of movement, without radiographic changes. Views on the underlying pathology vary. Watson-Jones (1955) states that "minor strains and contusions often cause traumatic synovitis of the elbow joint in children." Adams (1958) suggests that the lesion is probably a strain of the capsule or a contusion of the periosteum.

Gaston, Smith, and Baab (1949), in a paper on fractures of the head of the radius, stress the importance of the associated haemarthrosis and recommend that aspiration should be part of the treatment of these fractures. This observation, together with the fact that radiologically similar injuries often pursue entirely different courses, led us to a long-term study of the role of the associated soft-tissue damage on the outcome from various types of elbow injuries. At this point speculation that a haemarthrosis might exist in even the most minor contusion injuries led to this investigation and preliminary report.

In a series of 200 elbow injuries varying in degree from sprains to the most severe fracture-dislocations which were examined and treated by us over a three-year period, 45 had been diagnosed by the casualty surgeons as "contusions." Nine were proved to be more serious ligamentous or bony injuries and others had to be excluded because the patients defaulted. We were left with 29 fully documented injuries in which the diagnosis of a simple contusion was certain. Fifteen were investigated by aspiration as soon after the injury as possible and none later than 48 hours after. The aspiration findings form the basis of this report. Fourteen contusion injuries were treated conservatively and we had intended that they should form a control series.

\section{Clinical Method}

Thorough clinical and radiological examination was carried out and repeated at intervals. The ranges of movement were accurately measured, using goniometers. Where it was thought justifiable, and particularly where aspiration was to be undertaken, a general anaesthetic was administered to facilitate examination of the joint for stability. Complete and repeated examination excluded from the series ligamentous injuries, missed crack fractures, and the more severe injuries. Only those cases followed to the final stage of recovery were included.

A simple "contusion" of the elbow-joint caused by direct or indirect violence is characterized by pain, slight swelling, and limitation of movement, principally in the extension/ flexion range. Any restriction in the supination/pronation range is transient. Some increase in local skin temperature may be found. Acute local tenderness is not present. Serial radiological examination is always negative. Where acute localized tenderness, marked swelling, or bruising (early

* Consultant Orthopaedic Surgeon, Law Hospital, Carluke.

+ Consultant Orthopaedic Surgeon, Glasgow Royal Infirmary. or late) is present more extensive damage than a simple joint contusion exists.

Aspiration.-After accurate measurement of elbow movements, and with the patient supine, the elbow was flexed to 100 degrees with the forearm lying across the patient's body. At a point midway between the tip of the olecranon and the anterior superior margin of the head of the radius a No. 1 or No. 2 serum needle was directed towards the centre of the antecubital fossa and introduced into the joint through the space between the capitellum, the head of the radius, and the anterior edge of the sigmoid notch of the ulna. It is important to note that as the elbow is extended this space becomes increasingly inaccessible. When recovery from the anaesthetic was complete the range of movements was again measured. Aspiration was always carried out within 48 hours of the injury.

Management.-The elbow was rested in a collar-and-cuff sling in comfortable full flexion. Early regular active movements were encouraged but physiotherapy was not employed. After a week, provided there was no pain, the sling was discarded.

\section{Results}

It is significant that all elbows aspirated showed the presence of an effusion (Table I). In 14 cases this was frank blood varying in amount from $0.5 \mathrm{ml}$. to as much as $25 \mathrm{ml}$. The fifteenth elbow contained synovial fluid. Table II shows the restriction of the extension/flexion range of movement in both groups and a highly significant recovery in range after aspiration (also Table I, col. 10). The mean restriction before aspiration was 80.7 degrees (standard deviation 33.4 degrees). After aspiration the mean restriction was 40.5 degrees (standard deviation 24.7 degrees), which approximated the initial range of restriction in the non-aspiration group (49.6 degrees).

The two groups, therefore, are not comparable for a controlled study, and in retrospect it would seem that on the whole we had inadvertently selected for aspiration those patients with more marked pain and restriction of movement. Where aspiration was repeated the fluid tended to become more synovial in character, which accords with Metcalfe's (1926) observations on traumatic haemarthrosis of the kneejoint.

The accompanying Chart illustrates the relation between "range regained" and "range restriction" of the aspiration group.

All cases in this series made a complete recovery and no case was complicated by infection.

Artificial Effusion.-To confirm that fluid within a joint can of itself limit range of movement, an effusion was produced in the elbow of a volunteer. A man aged 28 had been operated on seven years previously for a fracture-dislocation of the elbow, when two screws were inserted across the olecranon. He was readmitted for removal of the screws and excision of a small overlying bursa. His immediate preoperative extension/flexion range was $168 / 40$ degrees. A brachial-plexus block was carried out without altering active movement at the elbow (Patrick, 1940). Into the joint $15 \mathrm{ml}$. of saline solution 
TABLE I.-Aspiration Series

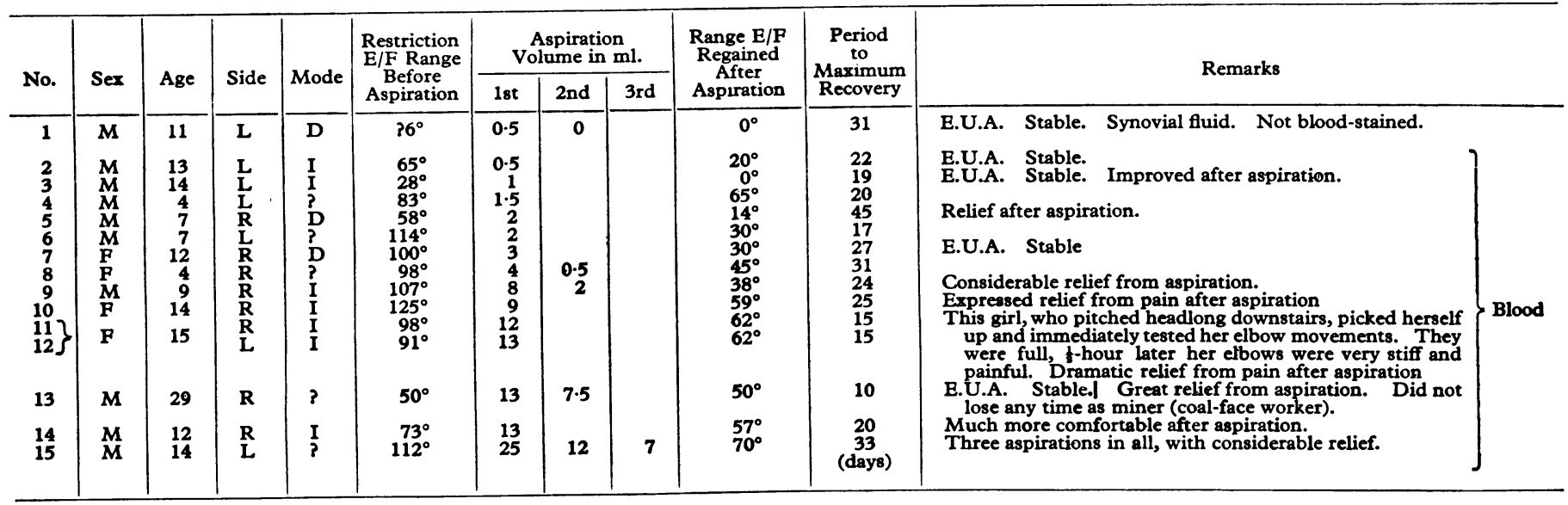

TABLE II.-Aspiration Group and Non-aspiration Group. Restriction of Movement (Extension/Flexion Range)

\begin{tabular}{|c|c|c|c|c|c|}
\hline & & & \multirow{2}{*}{\multicolumn{2}{|c|}{$\begin{array}{c}\text { Aspiration } \\
\text { Initial Loss }\end{array}$}} & Non-aspiration \\
\hline & & & & & \multirow{2}{*}{ Initial Loss } \\
\hline & & & Before & After & \\
\hline $\begin{array}{l}\text { Mean } \\
\text { Standard deviation }\end{array}$ & $\because$ & $\because$ & $\begin{array}{l}80 \cdot 7^{\circ} \\
33 \cdot 4^{\circ}\end{array}$ & $\begin{array}{l}40 \cdot 5^{\circ} \\
24 \cdot 7^{\circ}\end{array}$ & $\begin{array}{l}49 \cdot 6^{\circ} \\
22 \cdot 2^{\circ}\end{array}$ \\
\hline No. of elbows $\quad .$. & $\ldots$ & $\ldots$ & \multicolumn{2}{|c|}{15} & 14 \\
\hline
\end{tabular}

This table shows the comparison between the restriction of the extension/flexion This table shem the major or aspiration group before and after aspiration range of movement in the major or aspiration group before and after
and also the initial restriction of the minor or non-aspiration group.

Table III.-Aspiration Series and Non-aspiration Series. Days to

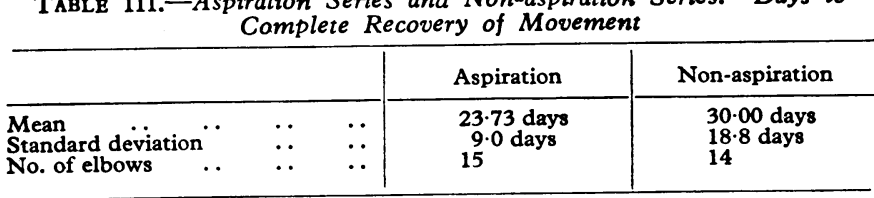

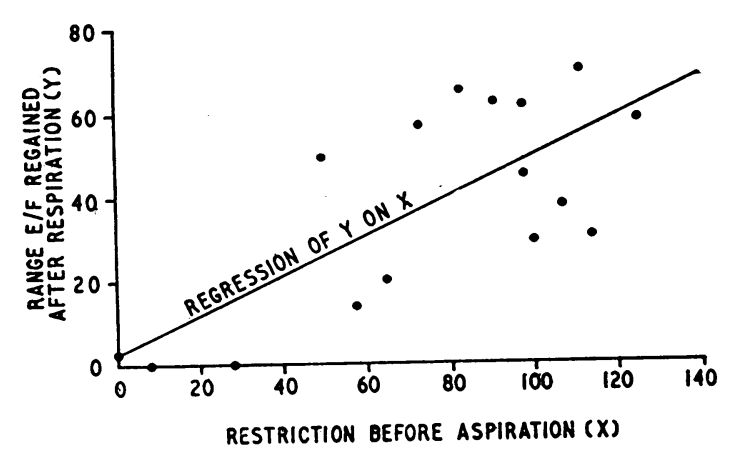

Showing relation between the restriction of the range of movement before aspiration and the range gained after aspiration. The correlation coefficient between $X$ and $Y$ is $r=0.68$, a value significantly different from $0 . \quad(P<0.01$.

was injected, his active range of movement being immediately reduced to $137 / 57$ degrees-that is, he had lost 48 degrees. The whole procedure was completely painless, and thus the restriction of movement was entirely mechanical. The fluid was aspirated and the operation concluded. He subsequently regained his full preoperative range of movement.

\section{Discussion}

The outstanding finding has been that all joints which were aspirated revealed an effusion. In 14 cases frank blood was obtained. The largest amount aspirated was $25 \mathrm{ml}$., which was out of all proportion to the slight swelling present. Most of these patients had suffered direct or indirect types of violence involving a contusing or impacting force. In only one case was the fluid synovial, and here the injury was associated with a twisting, distracting force. The presence of a joint effusion in these minor "contusion" injuries explains certain aspects of the clinical picture and suggests a rational line of treatment.

The onset of persistent pain and increasing stiffness half an hour after the initial discomfort had passed off was described by some of our patients. This is exactly the pattern found in acute haemarthrosis of the knee-joint, presumably signifying gradual distension of the joint. The relief from pain after aspiration has sometimes been dramatic.

The degree of pain and the amount of restriction in the extension/flexion range would seem to be a more reliable expression of the volume of the effusion than is the amount of swelling present. In the young or the very apprehensive patience is required in eliciting the true limits of extension and flexion. By diminishing the volume of fluid in the joint, aspiration immediately restores most of the movement that has been lost.

The origin of the bleeding is conjectural. It could arise from fat-pads, synovial fringes, the perichondrium, or the periosteum, all of which have a good blood-supply.

The potential danger of a joint haemarthrosis has long been discussed. Willems (1909), the "father of aspiration treatment," was the first to observe the importance of the rapid restoration of function by immediate aspiration.

The late hazards of a persistent haemarthrosis in the knee have been discussed by many writers. Brickner and Milch (1926) described significant macroscopic and microscopic changes in the synovium. The rapid development of a chronic synovitis, of intra-articular adhesions (Smillie, 1962), and of loose bodies (Metcalfe, 1926) have also been postulated. In this series, though admittedly the duration of observation has not been lengthy, we found no evidence to suggest that the elbow-joint could not readily absorb a haemarthrosis unaided and make a full and lasting recovery. It would seem, therefore, that for most contusions conservative management without aspiration is appropriate. The aim of this paper is to record the presence of an haemorrhagic joint-effusion in contusions of the elbow and to advocate aspiration only in those cases with severe pain and marked limitation of movement (Table I).

\section{Summary}

A contusion injury of the elbow is defined. The results of aspiration in 15 such cases are detailed. Haemarthrosis was demonstrated in 14 cases and a synovial effusion in one case. The clinical features of a contusion are correlated with the presence of a joint-effusion. The effect of an intra-articular 
injection of saline on joint movement is described in one case. The therapeutic application of aspiration of those minor joint injuries must be strictly limited.

We wish to thank Dr. R. A. Robb, Senior Lecturer in Statistics, Mathematics Department, University of Glasgow, for his statistical evaluation of the results. We are grateful to Mrs. M. Morton, Miss C. Bolton, and Miss C. Muir for their help in the preparation of this article.
REFERENCES

Adams, J. C. (1958). Outline of Fractures, Including foint Injuries, 2nd ed., p. 70. Livingstone, Edinburgh.

Brickner, W . Gaston, S. R., Smith, F. M., and Baab, O. D. (1949). Amer. ' 7 . Surg., 78, 631 .

Metcalfe, R. F. (1926). Surg. Gynec. Obstet., 34, 270.

Patrick, J. (1940). Brit. Y. Surg., 27, 108, 737.

Smillie, I. S. (1962). Injuries of the Knee foint, 3rd ed., p. 26. Livingstone, Edinburgh.

Watson-Jones, Sir R. (1955). Fractures and foint Injuries, 4th ed., 2, 509. Livingstone, Edinburgh.

Willems, Ch. (1909). Arch. int. Chir., 4, 5, 423.

\title{
Immunological Aspects of a Population under Prophylaxis Against Malaria
}

\author{
A. VOLLER,* M.SC., PH.D. ; H. WILSON,* M.R.C.S., L.R.C.P., D.C.H., D.T.M.\&H.
}

Brit. med. F., 1964, 2, 551-552

Since the demonstration by Cohen et al. (1961) of the therapeutic effect of malaria-immune gamma-globulin there has been growing interest in the part played by humoral immunity in malaria. Tobie et al. (1962) showed that the course of antibody production could be measured, using the fluorescent antibody technique, in subjects experimentally infected with malaria. Similarly, Voller and Bray (1962) were able to assess the antibody levels in residents of a malaria hyperendemic area of West Africa. These authors noted high malarial antibody titres in cord blood. Their inference that there was a passive transfer of maternal antibody across the placenta was borne out by the demonstration of Edozien et al. (1962) that the gammaglobulin from cord blood had a therapeutic effect on acute malarial infections.

The present preliminary study was undertaken in order to investigate the effects of drug treatment on malarial antibody production in infants and their mothers.

\section{Methods and Results}

The study was carried out at Sukuta, Gambia, West Africa, an area of hyperendemic falciparum malaria. A group of pregnant women were kept under observation at the weekly clinic at Sukuta. From the time of birth of their children or a few months later (see Table) these women and their infants were regularly given once-weekly oral Daraprim (pyrimethamine) (group 1: mothers $25 \mathrm{mg}$. weekly, children $12.5 \mathrm{mg}$. weekly) or placebo (group 2). There were seven mothers and children in each group.

Blood films were examined at regular intervals for malaria parasites. None of the women and only one child, Boobacar Bojang, of Group 1, showed parasitaemia. All the children except Sanna Cham and all the women in group 2 showed parasites at some time during the study period.

In December 1963 finger-prick blood samples were taken into microhaematocrit tubes and the serum was separated and made up to an initial dilution of $1: 25$ (McGregor and Voller, unpublished observations). The indirect fluorescent antibody test was then used to measure the levels of malarial antibody in the sera (Voller and Bray, 1962). Slide antigens used in these tests were thin blood smears taken from children with heavy - Department of Parasitology, London School of Hygiene and Tropical
Medicine and M.R.C. Laboratories, Gambia. infection of Plasmodium falciparum. The slides were stored at $-70^{\circ}$ C. until the day they were used.

The results of the antibody determinations are given in the Table.

\section{Discussion}

In this study malarial antibody was demonstrated in all but one of the unprotected children. In contrast, malarial antibody was not found in any of the infants who had been on antimalarial drug prophylaxis since birth. The average titre of the protected mothers was much lower than that of the unprotected group.

The unprotected children had an average antibody level which was considerably lower than that of their mothers. This is in agreement with the findings of Voller and Bray (1962), who showed that, although children in an endemic area are born with high malarial antibody levels, these drop over the first few months of life. Thus it would appear that the passively transferred maternal gamma-globulin is only short-lived.

This latter point is emphasized by the fact that none of the protected children had detectable antibody, although every

Malarial Antibody Analysis of Protected and Unprotected Mothers and Children in Gambia

\begin{tabular}{|c|c|c|c|c|c|c|}
\hline \multicolumn{4}{|c|}{ Child } & \multicolumn{3}{|c|}{ Mother } \\
\hline Name & $\begin{array}{c}\text { Age } \\
\text { in } \\
\text { Months }\end{array}$ & $\mid \begin{array}{c}\text { Protec- } \\
\text { tion } \\
\text { Period } \\
\text { in } \\
\text { Months }\end{array}$ & $\begin{array}{l}\text { F.A. } \\
\text { Titre }\end{array}$ & Name & $\begin{array}{c}\text { Protec- } \\
\text { tion } \\
\text { Period } \\
\text { in } \\
\text { Months }\end{array}$ & $\begin{array}{l}\text { F.A. } \\
\text { Titre }\end{array}$ \\
\hline
\end{tabular}

\begin{tabular}{l|r|r|r|l|r|r}
\hline \multicolumn{7}{c}{ Group 1: Protected Individuals } \\
Lamin Colley .. & 7 & 7 & $<25$ & Naffe Colley .. & $6 \frac{1}{2}$ & 25 \\
Boobacar Bojang & 10 & 9 & $<25$ & Awa Darameh & 7 & 25 \\
Adams M'Boob & 12 & 9 & $<25$ & Amie Fye & 7 & 400 \\
Ousman Cham... & $4 \frac{1}{2}$ & $4 \frac{1}{2}$ & $<25$ & Yasule Manneh & 4 & 200 \\
Abdouli Sanyang & 9 & 9 & $<25$ & Mariama Dibba & 7 & 100 \\
Bakari Kammara & 12 & 9 & $<25$ & N'Yonko Cham & 7 & 100 \\
Saku Sanko .. & 7 & 7 & $<25$ & Isature Sanyang & 7 & 25 \\
\hline Average & $8 \frac{1}{2}$ & $7 \frac{1}{2}$ & $<25$ & & $6 \frac{1}{2}$ & 125 \\
\hline
\end{tabular}

\begin{tabular}{|c|c|c|c|c|}
\hline \multicolumn{5}{|c|}{ Group 2: Unprotected Individuals } \\
\hline $\begin{array}{l}\text { Momadu Cham. } \\
\text { Lamin Bojang }\end{array}$ & $\begin{array}{r}11 \\
9 \\
11 \\
7 \\
9 \\
10 \\
6\end{array}$ & $\begin{array}{r}200 \\
100 \\
100 \\
50 \\
25 \\
200 \\
<25\end{array}$ & $\begin{array}{l}\text { Manta Jaju .. } \\
\text { Isatou Sanneh } \\
\text { Manyima Cham } \\
\text { Fatou Sanko .. } \\
\text { Manta Bojang } \\
\text { Fatou Touray.. } \\
\text { Awa Cham .. }\end{array}$ & $\begin{array}{l}200 \\
400 \\
400 \\
400 \\
100 \\
800 \\
400\end{array}$ \\
\hline Average & 9 & 100 & & 385 \\
\hline
\end{tabular}

